\title{
Free Session
}

\section{Return Migration from Sweden to Finland in 1946-1970}

\author{
By KIMMO MIKKOLA \\ Central Statistical Office of Finland
}

\section{Introduction}

The study of return migration from Sweden resembles the analysis of the part of an iceberg visible at sea level. Only a very small portion of the actual phenomenon under study is visible. The nature of this visible portion cannot be understood without also knowing something of the Finnish migrants remaining in Sweden and of the process which caused this iceberg to break off.

Return migration can be examined as both a phenomenon of selection and of being selected. Both reveal part of the truth. Not all emigrants are disappointed in their expectations and find, after living in Sweden for a while, that their own country is the better alternative, after all. The reasons that some are disappointed are not known at the moment. Only some of these people actually have the necessary qualifications to return. They must be able to compete on the Finnish labor market with the Finnish labor force, and not all of these people are up to this because they are not skilled enough.

On the basis of a survey made in Sweden there is a marked willingness among Finns in Sweden to move back to Finland. $15 \%$ of the Finnish citizens who had moved to Sweden in 1961-1968 and still lived there in 1969 said they planned on returning to Finland and $44 \%$ had not yet made up their minds (Wadensjö 1972, 98). $27 \%$ of those who emigrated to Sweden in 1960-1970 returned to Finland during the same period (Historisk statistik för Sverige, Del 1, S C B 1969, 126; Befolkningsförändringar 1968, 1969, 1970, Del 3).

In a way, return migration reflects an adjustment between the demand level of the re-migrants and the demand level of Finland, mainly that of Finland's labor market. Finnish employers will not accept workers returning from Sweden unless they are equally as qualified through work experience and skills as the workers available in Finland. People will not return permanently to Finland unless the wage level, type of work, housing conditions, and in addition, the schooling available to their children, social status and other factors affecting the quality of life are at least equal to the conditions the emigrants have reached in Sweden. 
The re-migrants and the employers who have accepted them have both had to adjust to the process of change which has taken place in Finnish society during the last few decades. Its most important features have been urbanization, the rise in the level of education, the change in the industrial structure and the occupational structure, and the migration to Uusimaa province. The problems of return migration are associated mainly with this process of change. In a way, re-migrants form a labor force coming from outside the Finnish economy and, in order to compete with the Finnish labor force, they must adjust to these processes of change much more frequently than the permanent inhabitants of the country. The demand for workers has been greatest in the urban industries, in Uusimaa province, in occupations whose skilled worker population has grown, in jobs demanding skilled labor, etc.

In the analysis of the empirical data we will try especially to examine the relationships between the processes of change that have taken place in Finland and the regional and occupational distribution of the re-migrants. However, the empirical data does not make it possible to make very far-reaching analyses.

\section{The Research Data}

The research data was obtained from the 1970 Finnish census. Because of the record-making migration of the 1960's and especially during the last few years of the decade, the Finnish census officials decided to gather basic information in connection with the census on the extent of return migration and, at the same time, to lay the foundation for eventual sampling studies. For these reasons the census contained one question meant for people who had worked in Sweden for at least six months that inquired into the length and decade of this stay $(1946-49,1950-59,1960-70)$. Answering this question, then, required that the person belonged to the population having worked in Sweden for at least six months. There were a total of 53787 answers.

Sixty percent of those who answered had been migrants either only in the 1960 's or in earlier decades and also in the sixties. In 1960-1970 net loss by way of emigration to Sweden was a total of 152000 people, so the return migration this research data consists of is only a small portion of the total migration. Most of the people had stayed in Sweden only a short time. About onethird had worked there for less than a year and $28 \%$ had worked there from 1-2 years.

Compared to the total population they were very young. Over-40-year olds comprised $41 \%$ of the total population and $20 \%$ of those who worked in Sweden. The employment criterion apparently caused the slantedness of the sex distributions $65 \%$ were men. The dissimilarity of the age and sex distributions as compared to the total population will cause difficulties in making future comparisons. 
The data on the employed can only be analyzed using the table programs made for the Finnish census. This greatly restricts the treatment of the data. The research strategy consists of research group - control group comparisons, the control group being the total Finnish population on December 30, 1970. The census table programs are listed after the bibliography.

\section{Regional Distribution}

The re-migrants do not noticeably differ from the total population in how they are distributed regionally by provinces. Most of them had been in Sweden for such a short time that no extensive departure from the distribution of the entire population can be expected. After a short period of emigration it is probably most likely that the emigrant returns to the place of departure.

M a p 1. The regional distribution by province and form of commune of the people who have worked in Sweden in 1946-1970.

The provinces of Turku, Pori, Häme, Kymi, and Uusimaa differ from the others because in these provinces the re-migrants have settled mainly in cities and townships. This is common among the people who have worked in Sweden. Fifty-one percent of the total Finnish population and fifty-nine percent of the remigrants lived in cities and townships.

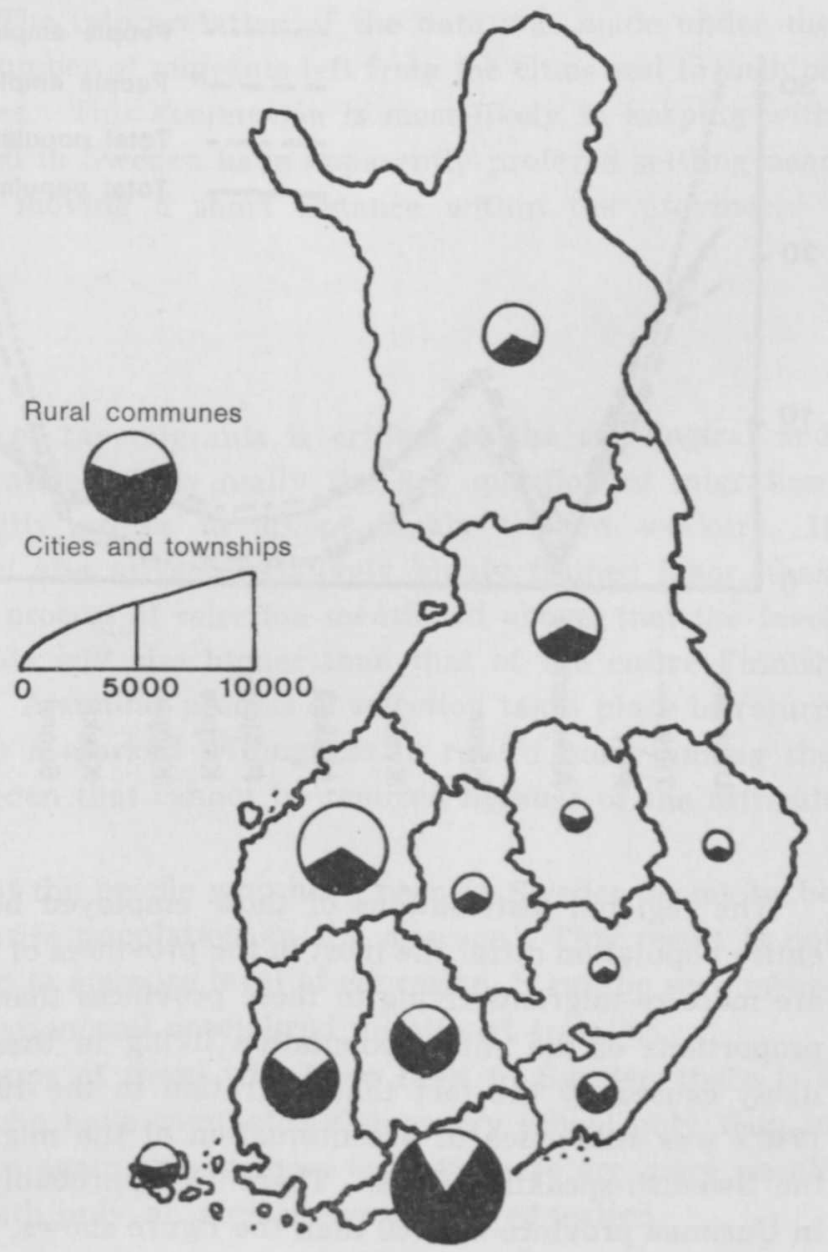


However, the regional distribution shows a quite distinct concentration in the coastal regions. This can be seen from Map 1, which shows the distribution of the re-migrants by province and form of commune.

Compared to the population of each province the largest number of re-migrants was found in Åland province $(8.3 \%$ ), Lappi province $(2.3 \%$ ) and in Vaasa province $(2.2 \%)$. The smallest number both absolutely and relatively lived in the eastern provinces.

The distribution of the re-migrants and of the entire population was then examined according to which decade they were employed. The distributions are shown in Figure 1, to which has been added, for comparison, the distribution of the entire population in 1960 .

Figure 1. The regional distribution by province of the people who were employed in Sweden in 1946-1959 and in 1960-1970 and of the entire population in 1960 and 1970.

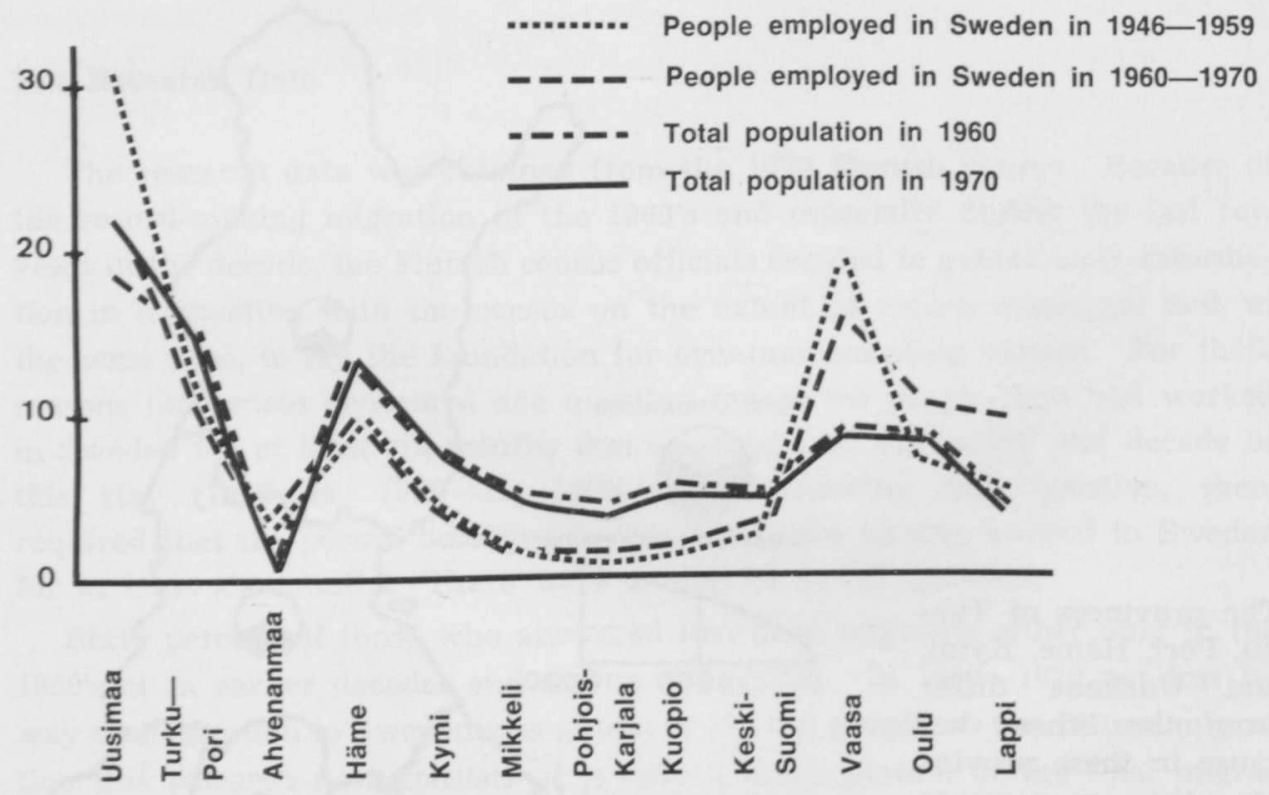

The regional distributions of those employed before the 1960's and of the entire population differ the most in the provinces of Uusimaa and Vaasa. There are more re-migrants living in these provinces than would be expected by the proportions of the entire population living in these provinces. This is most likely caused by the fact that migration in the 1950's and at the end of the 1940 's was still much of a continuation of the migratory tradition existing in the Swedish-speaking areas. There were probably fewer re-migrants living in Uusimaa province in 1960 than the figure shows, because many of the people 
who had migrated before the 1960's may have moved to Uusimaa province during the 1960's. For the opposite reason, the proportion shown living in Vaasa province is lower than it actually was.

The distribution of those employed in the 1960's is more similar to the distribution of the entire population. The proportion in Uusimaa province has decreased to the level of the entire population. The proportion returning to Lappi province has grown, which suggests that the migration of the 1960's was typical of the underdeveloped regions of Northern Finland, in addition to the old emigration regions. Intermobility from province to province seems to have been rather slight among the re-migrants. This is suggested by the fact that their distribution is similar to the regional distribution of the entire population.

The higher proportion of re-migrants living in cities and townships indicates that intraregional migration has takes place. Sixty-three percent of the people who had been to Sweden before the 1960's lived in cities and townships as did $57 \%$ of those who had been there during the 1960's. Even when examined separately by provinces, the proportion of re-migrants is higher in cities and townships than is the proportion of the entire population on the average in almost all the provinces. The interpretation of the data was made under the assumption that an equal number of migrants left from the cities and townships as from the rural communes. This assumption is most likely in keeping with reality. People who worked in Sweden have apparently prefered settling near growing urban industries, moving a short distance within the province.

\section{Level of Education}

The level of education of the migrants is critical to the sociological and economical nature of migration. It is really the key question of migration. Swedish employers naturally prefer to accept highly trained workers. If Sweden's higher wage level also attracts relatively highly trained labor, then it follows by means of the process of selection mentioned above, that the level of education of the migrants will rise higher than that of the entire Finnish population on the average. A similar process of selection takes place in return migration, because there is a marked willingness to return home among the Finnish immigrants in Sweden that cannot be realized because of the difficult labor situation in Finland.

The level of education of the people who have been in Sweden seems to be higher than that of the entire population on the average. This result is not affected by the method used to measure level of education. It can be seen measured in both level of education and specialized vocational training.

In the younger age groups of those who have been in Sweden there is a relatively larger number who have completed elementary school only than in the entire population. Then again among those over 40 there are more people in the entire population with only an elementary school education. 
$\mathrm{T}$ a ble 1. Skilled population previously employed in Sweden and entire skilled population according to age and level of education.

\begin{tabular}{|c|c|c|c|c|c|c|c|c|c|c|}
\hline & \multicolumn{5}{|c|}{$1946-1970$} & \multicolumn{5}{|c|}{ Entire skilled population } \\
\hline & -19 & $20-29$ & $30-39$ & $40-49$ & $50-$ & -19 & $20-29$ & $30-39$ & $40-49$ & $50-$ \\
\hline Elementary school & 71 & 51 & 58 & 61 & 64 & 67 & 45 & 57 & 71 & 76 \\
\hline $\begin{array}{l}\text { Higher basic } \\
\text { school level and } \\
\text { lower secondary }\end{array}$ & & & & & & & & & & \\
\hline level & 28 & 35 & 26 & 21 & 17 & 32 & 37 & 24 & 17 & 14 \\
\hline $\begin{array}{l}\text { Higher secondary } \\
\text { level and higher } \\
\text { education }\end{array}$ & 1 & 14 & 16 & 18 & 19 & 1 & 18 & 19 & 12 & 10 \\
\hline & 100 & 100 & 100 & 100 & 100 & 100 & 100 & 100 & 100 & 100 \\
\hline
\end{tabular}

In examining the results, it must be taken into account that those returning from Sweden are, on the average, very young: most are under 30 . About $70 \%$ of the over 40-year-olds had been in Sweden before the 1960's. Their level of education reflects, then, the migration of the 1950's and of the young people who migrated after the war. During this period emigration was still perhaps somewhat of a novelty and it was governed by the migratory traditions of the Swedish-speaking areas relatively more than the emigration of the sixties. The level of education of the emigrants of the fifties was probably higher than it is now.

The variance with age noted above is similar to that evident in the dichotomous classification into specialized vocational training and no specialized vocational training.

$\mathrm{Table} 2$. Percentages according to age of those having received specialized vocational training. Entire population over 14 and those re-migrants employed in Sweden in 1946-1970.

$\begin{array}{lcc}\text { Age } & 1946-1970 & \begin{array}{c}\text { Population over } \\ 14 \text { years of age }\end{array} \\ -19 & 15.0 & 9.8 \\ 20-29 & 37.1 & 37.8 \\ 30-39 & 34.0 & 31.6 \\ 40-49 & 31.0 & 19.7 \\ 50- & 25.6 & 12.3 \\ \text { Tot a 1 } & 32.6 & 21.7\end{array}$


In the youngest age groups the difference between the re-migrants and the entire population is caused by the fact that the employment criterion left out the 14-16 year-olds among the re-migrants, who because of their youth has not yet had time to receive their vocational training. The difference between those over 40 and the entire population is already very noticeable.

The level of education of those having worked in Sweden can be examined regionally using those who have completed secondary school. An exact comparison with the entire population cannot be made, because the re-migrants are younger and the level of education in Finland has risen markedly in the last few decades (see Table 1). Nevertheless, for comparison, the following table also shows the percentages of the entire population aged 15 and over who have completed at least secondary school.

T a ble 3. Percentages by province and form of commune having completed at least secondary school. Re-migrants and the entire population aged 15 and over.

$1946-1970$

Province of residence

Uusimaa

Turku-Pori

Ahvenanmaa

Häme

Kymi

Mikkeli

Pohjois-Karjala

Kuopio

Keski-Suomi

Vaasa

Oulu

Lappi

Entire country

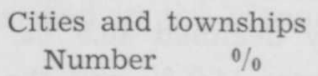

Rural communes Number $\%$

$\begin{array}{rr}636 & 23.4 \\ 323 & 17.4 \\ 52 & 6.6 \\ 277 & 19.2 \\ 125 & 21.8 \\ 97 & 22.0 \\ 58 & 11.3 \\ 74 & 15.2 \\ 118 & 11.4 \\ 416 & 6.7 \\ 245 & 8.3 \\ 195 & 6.9 \\ 2616 & 12.0\end{array}$

Entire population aged 15 and over

Cities, Rural townships communes Number

$\begin{array}{rr}23.1 & 17.5 \\ 21.6 & 11.3 \\ 24.8 & 6.4 \\ 20.6 & 13.0 \\ 18.8 & 10.5 \\ 21.4 & 9.2 \\ 20.3 & 9.2 \\ 18.9 & 9.6 \\ 22.7 & 12.2 \\ 21.8 & 10.9 \\ 22.8 & 10.8 \\ 20.6 & 10.4 \\ 25.2 & 11.7\end{array}$

The percentage having completed secondary school is higher among the re-migrants than in the entire population aged 15 and over. There are relatively fewer people having completed secondary school only among the re-migrants, as compared to the entire population of the respective province in the provinces of Åland, Vaasa, Oulu and Lappi. Common to all of these provinces is their vigorous migration as compared to the number of inhabitants, at the end of the 1960's and in 1970 (see Häggström 1972, 63). 
The circumstances giving rise to vigorous migration caused, at the same time, either less than average return migration of highly trained people to the areas they had left or then, as migration increases, the average level of education among the migrants begins to decline. When the probably quite slight regional migration among the migrants from one province to another is taken into account then the latter explanation seems more probable.

For the migration problem, the most important result of those mentioned above is that the level of education of those who have returned is at least as high as that of the entire population on the average. The most theoretically interesting result is the interdependency of the quantitive variance of migration and the level of education of the migrants declines. This result or rather this kind of interpretation was arrived at because of the higher level of education of the migrants of the 1950's (in the fifties net migration was half of what it was in the sixties) and the lower level of education of those returning to high-migration provinces in the 1960's.

\section{Industrial and Occupation Distribution}

Finland's industrial structure changed immensely in the 1960 's. The number of skilled workers in farming and forestry declined $40.5 \%$, the number in transportation and commerce (I S I C 6, 8) rose $44.9 \%$ and the number in the service industries (I S I C 9) rose $46.6 \%$.

On returning to Finland, the re-migrants' best opportunity to find a job is in those industries that are expanding and therefore need more workers. Taking into consideration their short length of stay, job placement probably does not take place right on their return, instead after having been in Finland a little while.

$\mathrm{Table}$ 4. Skilled re-migrant population and entire skilled population according to sex and the change in the number of people working in the different occupations in 1961-1970.

\begin{tabular}{lcccc}
$\begin{array}{l}\text { Occupational groups according } \\
\text { to change in skilled worker } \\
\text { population }\end{array}$ & Men & Women & \multicolumn{2}{c}{$\begin{array}{c}\text { Entire skilled } \\
\text { population }\end{array}$} \\
$\begin{array}{l}\text { Occupations that have } \\
\quad \text { increased the most }\end{array}$ & 19.8 & 47.5 & 17.9 & 39.4 \\
$\begin{array}{l}\text { Other occupations that } \\
\text { have increased }\end{array}$ & 54.9 & 41.6 & 51.3 & 40.4 \\
$\begin{array}{l}\text { Occupations that have } \\
\text { decreased }\end{array}$ & 25.3 & 10.9 & 30.8 & 20.2 \\
Total & 100.0 & 100.0 & 100.0 & 100.0
\end{tabular}


The decrease in the proportion of the population working in farming and forestry is also reflected in the industrial structure of the re-migrants. They make up $7 \%$ less of the farm and forestry workers than does the rest of the skilled population. Among those over 40 the difference is $13 \%$. Seven percent more of the men who had been in Sweden were now working in industry (I S I C 2-5), and for women under-representation in farming (I S I C 6, 8) was compensated by over-representation in the service industries (I S I C 9).

The different distribution of the re-migrants became even more evident on analysis by occupations. Occupations stated on the $2-$ number-level were grouped into three parts according to the increase of workers in these occupations during the 1960 's. After that the distributions by occupation and sex were calculated for those who had been in Sweden and the entire population.

The difference among women is much larger than among men. In the occupational groups the difference is much larger in occupations whose skilled population has decreased.

The fact that the re-migrants can be securely placed in occupations whose worker population has increased is not caused by their being somehow more qualified for these occupations. Those who have been in Sweden have received a more than average amount of vocational training in all three of the occupational groups formed in the manner mentioned.

Table 5. Skilled re-migrant population and entire skilled population according to percentages having received specialized vocational training and the change in the number working in the different occupations in 1961-1970.

Occupational groups according to change in skilled worker population
Percentage having received specialized vocational training

$$
1946-1970
$$

23.0

34.2
Entire skilled population

31.8

34.4

16.1

28.9

31.8
34.4
16.1
28.9

Other occupations that have increased

Occupations that have decreased

Tot a 1

The statistics do not show whether the specialized vocational training suits the occupation the person is in. The formation of this type of statistics would, in practice, be quite impossible. Nevertheless, the table shows that on the average, the re-migrants have received vocational training more often in most of the occupations they are in. 


\section{Conclusions}

The relatively high level of education of the re-migrants and their occupational distribution compared to the entire Finnish skilled population more often than average into rapidly expanding occupations shows that people who have also had good job opportunities in Finland have gone to Sweden to try out the job opportunities offered by the Swedish economy. Placement in the Finnish job market cannot have been significantly helped by having worked in Sweden, because for most the stay in Sweden was very short. With Southern Finland suffering from a lack of skilled workers, migration, if it continues, can actually become an obstacle to economic development. In relation to the number of inhabitants the largest number of migrants left from Northern Finland, but a relatively large amount of migrants left from Uusimaa province, which is suffering from a labor shortage (see Mikkola 1973 appendix tables 11 and VI).

The results suggested that as migration decreases its detrimental effects do not decrease at the same rate as the number of migrants. A very simple explanation can be found for this. A time-series analysis made in the Ministry of Labor showed that in the 1960's the number of emigrants leaving for Sweden depended almost entirely on the number of jobs available in Sweden. The labor situation in Finland had no effect (Sääski 1969, 18-22). In the 1960's there were always as many people leaving for Sweden as Swedish employers could accept, even when there was a boom period in Finland. As the labor situation became more difficult in Sweden, the migrants were faced with tougher work skill requirements than in the good years, and the higher level of education of the re-migrants shows that people who had received vocational training were also ready to leave for Sweden.

\section{References}

Statistical tables made using census programs concerning the people who worked in Sweden in 1946-1970:

Working population according to occupation and level of education 31.12.1970.

Population according to main language, level of schooling and age 31.12.1970.

Population according to year of birth, marital status and sex 31.12.1970.

Population aged 14 and over according to field and level of schooling 31.12.1970.

Population aged 14 and over and working population according to occupation and vocational training (field and level of schooling) 31.12.1970.

Population according to age, length of job occupation in Sweden and year of stay 31. 12. 1970.

Population according to main occupation, marital status, industry and age 31.12.1970. 